\title{
Heparin-Like Drugs with Antiangiogenic Activity
}

\author{
María Rosa Aguilar, Luis García-Fernández, \\ Raquel Palao-Suay and Julio San Román \\ Biomaterials Group, Polymeric Nanomaterials and Biomaterials Department, \\ Institute of Polymer Science and Technology (CSIC), Madrid \\ Biomedical Research Networking Centre in Bioengineering, \\ Biomaterials and Nanomedicine (CIBER-BBN)
}

Spain

\section{Introduction}

The process of angiogenesis consists in the sprouting of new blood vessels from existing ones. This is a natural process that occurs in the human body and is essential for organ growth and repair. In the embryonic stage, the blood vessels provide the necessary oxygen, nutrients and instructive trophic signals to promote organ morphogenesis (Coultas et al., 2005). After birth the angiogenic process only contributes to organ growth and during adulthood the angiogenic process only occurs in the placenta during the pregnancy and in the cycling ovary, while most blood vessels remain quiescent. However the angiogenic activity could be reactivate because endothelial cells retain their angiogenic activity in response to a physiological stimulus (wound healing and repair) (Alitalo et al., 2005).

This angiogenic activity is also critical in the development of solid tumors and metastasis (Ferrara, 2004; Folkman, 1990). Generally, a solid tumor expands until 1-2 $\mathrm{mm}^{3}$ is reached. At this point vascularization is required in order to ensure a supply of nutrients, oxygen, growth factors and proteolytic enzymes to the tumor (Folkman, 1990). To activate the angiogenic activity of endothelial cells, the tumor switches to an angiogenic phenotype and recruits blood vessels from the surrounding tissue, developing a dense vasculature that provides nutrients to the cancerous tissue (Figure 1). Numerous proangiogenic proteins are involved in tumor angiogenesis.

Two of the most important families of pro-angiogenic proteins are the vascular endothelial growth factors (VEGF) and the fibroblast growth factors (FGF) (Garcia-Fernandez et al., 2010c). Most of these GF isoforms (this is not the case of the smallest isoform of VEGF-A (V121), that does not present a heparin-binding domain) need to interact with heparan sulfate proteoglycans molecules (HSPG) in order to recognize their specific tyrosine kinase receptor on cell membrane and activate the angiogenic process. These cell surface molecules are low affinity receptors that do not transmit a biological response, but are essential for these growth factors to recognize their union site to the signaling receptor (FGFR or VEGFR). Therefore, disruption of the interaction of these growth factors (GF) with cell surface HSPG seems an evident target for angiogenesis (Folkman, 1971; Folkman, 1990; Folkman, 1995).

HSPGs are heparin-like molecules that favor the pro-angiogenic proteins oligomerization (Figure 1), which is necessary for the interaction with the endothelial cells membrane 
receptors. Heparin is a natural polysaccharide composed of alternating units of sulphated glucuronic acid and glucosamine derivatives, it presents anticoagulant activity and interacts with the most important pro-angiogenic proteins in tumor angiogenesis (e.g. different isoforms of FGF and VEGF) (Fernández-Tornero et al., 2003; Lindahl et al., 1994).

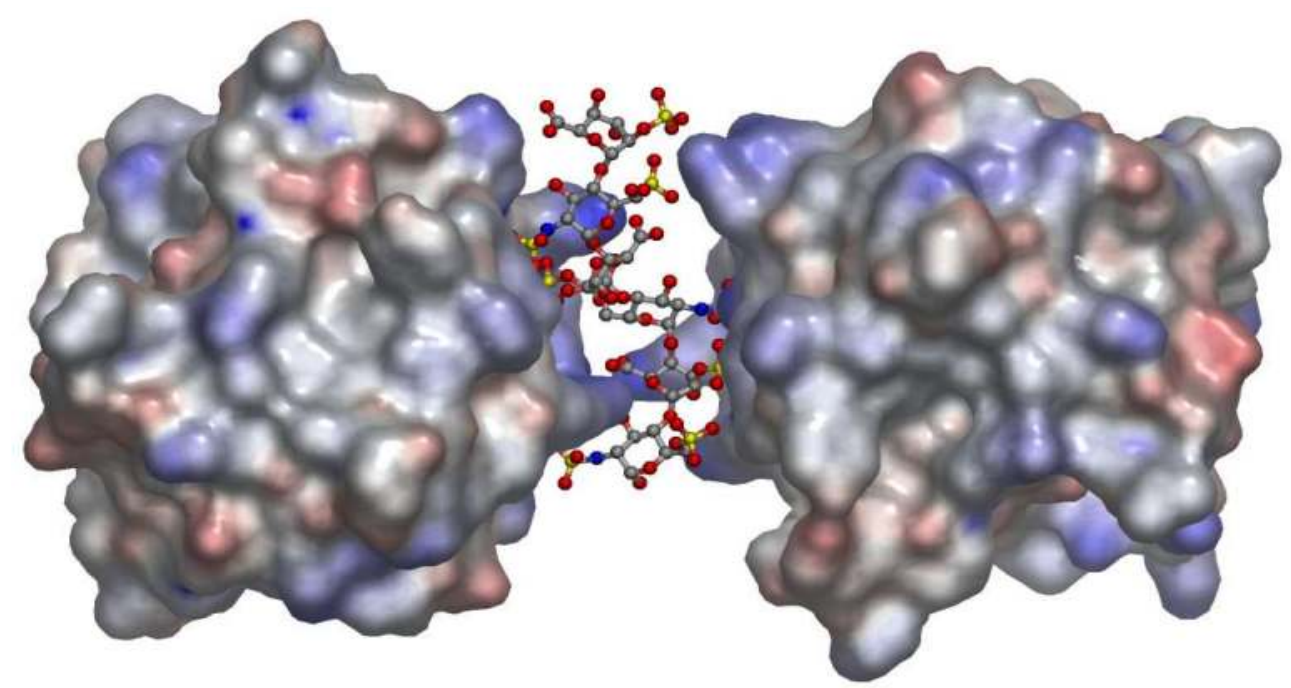

Fig. 1. Structure of a heparin-linked biologically active dimer of acidic fibroblast growth factor. Heparin is shown as stick-and-ball model (carbon: grey; oxygen: red; sulfur: yellow; nitrogen: blue). The figure was generated and the surfaces colored according the electrostatic potential (red, negative; blue, positive) using OpenAstexViewer (3.0; Astex Therapeutics Ltd.) and its internal parameters. PDB ID: 1AXM (DiGabriele et al., 1998).

The interaction between heparin and "heparin binding-proteins" (those that present a heparin-binding domain) regulates most of the biological properties of this sulfated glycosaminoglycan (GAG). However, angiogenesis is a complicated process regulated by numerous biologically active molecules and through different pathways that cannot be explained without each other (Figure 2). The ideal heparin-like drug to be designed for the treatment of tumor angiogenesis not only will interact with angiogenic growth factors (FGF-1, FGF-2, VEGF...) reducing their functional activity, but also will inhibit heparanase preventing the release of these growth factors from the extracellular matrix (ECM) and stimulate tissue factor pathway inhibitor (TFPI) conferring an antimetastatic character to the molecules. Heparanase is an endo- $\beta$-D-glucuronidase capable of cleaving the heparan sulfate (HS) side chains of HSPG, playing a key role in ECM-remodelling and heparinbinding release, and TFPI is a potent anticoagulant and antiangiogenic endogenous polypeptide.

In this chapter, the most recent studies for the design of heparin-like drugs will be reviewed starting with the effect of different heparinoids (low molecular weight heparins (LMWH) and chemically modified heparins) and finishing with the activity of synthetic antiangiogenic molecules. Many of these studies demonstrate that the biological activity of these heparinlike drugs depends on composition (charge density), microstructure (charge distribution), 
molecular weight, and the supramolecular organization (charge orientation) of the polymers (Garcia-Fernandez et al., 2010b; Garcia-Fernandez et al., 2010c). Most of the clinically investigated therapies target VEGF or one of its receptors (e.g. Bevacizumab or Avastin, a recombinant humanized monoclonal IgG1 (anti-VEGF-A) antibody) (Wahl et al., 2011), however the development of new compounds that interact with pro-angiogenic molecules through heparin-binding domains is a good strategy to obtain new therapeutics with synergistic inhibitory effect of not one but several pro-angiogenic molecules (broadspectrum angiogenesis inhibitors).

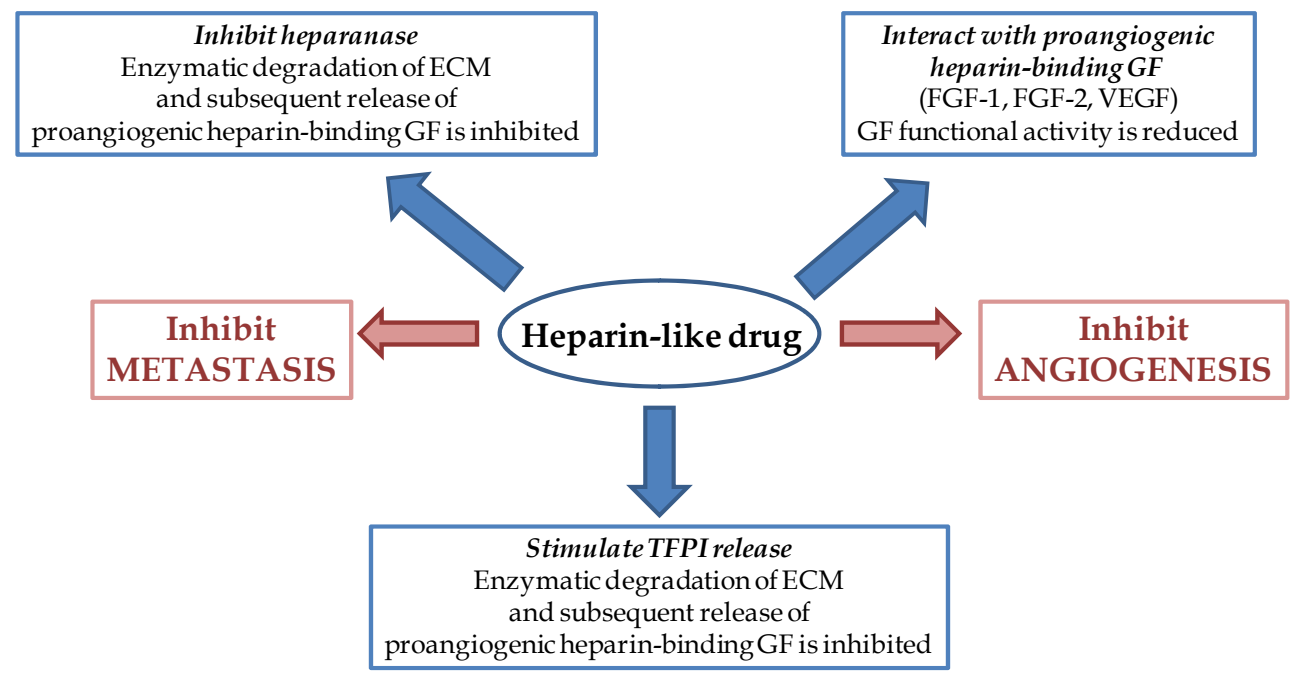

Fig. 2. Possible effects of heparin-like drugs for the treatment of tumor angiogenesis: interaction with proangiogenic heparing-binding growth factors, inhibition of heparanase and stimulation of TFPI release.

\section{Heparin species (heparinoids)}

Heparin presents very interesting pharmacological actions including antitumor and antimetastatic activity, however its use as anticancer agent has been limited due to the high risk of bleeding complications because of its anticoagulant and antithrombotic properties. Several efforts have been performed in the last decades in order to mimic and specifically modulate the biological action of heparin by exogenous heparin species (i.e. unfractionated heparin, LMWH, heparin oligosaccharides, chemically modified heparins and biotechnologically obtained heparins). Fortunately, heparin modification allowed the creation of new heparinoids with non-anticoagulant activity but antiheparanase activity and ability to interact selectively with proangiogenic growth factors. As it will be demonstrated molecular weight, charge density and charge distribution of heparin play a key role in its biological activity.

\subsection{Low molecular weight heparins (LMWH)}

LMWH are derived from unfractionated heparin (UFH) by chemical or controlled enzymatic depolymerization and present a lower mean molecular weight between 3 and $6 \mathrm{kDa}$ and 
chain lengths of 12 to 18 saccharide units. LMWHs have been available in Europe since the mid-1980s. In 1993 the first LMWH was approved in the United States for the treatment of venous thrombus (Grande \& Caparro, 2005; Kakkar, 2004).

Since are prepared by different methods of depolymerization, they differ to some extent in pharmacokinetic properties and anticoagulant profile, and may not be clinically interchangeable (Hirsh et al., 2001; Norrby, 2006).

LMWH present important advantages if compared to UFH: enhanced bioavailability after subcutaneous administration, prolonged half-life and more interesting pharmacokinetic properties, reduced thrombocytopenia and a more predictable dose response (Grande \& Caparro, 2005; Khorana et al., 2003).

\begin{tabular}{|c|c|c|c|c|c|}
\hline $\begin{array}{l}\text { Generation } \\
\text { heparin }\end{array}$ & Name & $\begin{array}{c}\text { Commercial } \\
\text { name }\end{array}$ & $\begin{array}{l}\text { Method of } \\
\text { preparation }\end{array}$ & \begin{tabular}{|c|} 
Mean \\
molecular \\
weight $(\mathrm{Da})$
\end{tabular} & References \\
\hline \multirow{5}{*}{$\begin{array}{c}\text { First } \\
\text { generation } \\
\text { heparin }\end{array}$} & Tinzaparin & Innohep & $\begin{array}{c}\text { Heparinase } \\
\text { depolymerization }\end{array}$ & 6.500 & $\begin{array}{c}\text { (Amirkhosravi et al., 2003; } \\
\text { Gasowska et al., 2009; Mousa } \\
\text { \& Mohamed, 2004a; Mousa \& } \\
\text { Mohamed, 2004b; Mousa \& } \\
\text { Petersen, 2009; Norrby, 2006) }\end{array}$ \\
\hline & Dalteparin & Fragmin & $\begin{array}{c}\text { Nitrous acid } \\
\text { depolymerization }\end{array}$ & 6.000 & \begin{tabular}{|c|} 
(Khorana et al., 2003; \\
Marchetti et al., 2008; Norrby, \\
2006; Norrby \& Nordenhem, \\
2010; Takahashi et al., 2005)
\end{tabular} \\
\hline & Enoxaparin & Clexane & \begin{tabular}{|c|} 
Benzylation and \\
alkaline \\
hydrolysis \\
\end{tabular} & 4.500 & \begin{tabular}{|c|} 
(Khorana et al., 2003; \\
Marchetti et al., 2008; Norrby, \\
2000; Norrby, 2006) \\
\end{tabular} \\
\hline & Nadroparin & Fraxiparin & $\begin{array}{c}\text { Nitrous acid } \\
\text { depolymerization }\end{array}$ & 4.500 & $\begin{array}{l}\text { (Debergh et al., 2010; Khorana } \\
\text { et al., 2003; Norrby, 2000) }\end{array}$ \\
\hline & Reviparin & Clivarine & $\begin{array}{c}\text { Nitrous acid } \\
\text { depolymerization }\end{array}$ & 4.500 & $\begin{array}{l}\text { (Collen et al., 2000; Gasowska } \\
\text { et al., 2009; Mousa \& Petersen, } \\
\text { 2009; Norrby, 2006) }\end{array}$ \\
\hline \multirow[t]{2}{*}{$\begin{array}{c}\text { Second } \\
\text { generation } \\
\text { heparin }\end{array}$} & Bemiparin & Badyket & \begin{tabular}{|c|} 
Chemical $\beta-$ \\
elimination \\
depolymerization
\end{tabular} & 3.500 & $\begin{array}{l}\text { (Depasse et al., 2003; Dogan et } \\
\text { al., 2011; Jeske et al., 2011; } \\
\text { Perez-Ruiz et al., 2002; Vignoli } \\
\text { et al., 2011; Westmuckett et al., } \\
\text { 2001) }\end{array}$ \\
\hline & $\begin{array}{l}\text { ULMWH } \\
(\mathrm{RO}-14)\end{array}$ & --- & $\begin{array}{c}\text { Chemical } \beta- \\
\text { elimination } \\
\text { depolymerization }\end{array}$ & 2.200 & (Vignoli et al., 2011) \\
\hline
\end{tabular}

Table 1. LMWH and ULWMW with antiangiogenic activity.

These advantages have led to their increasing use in the treatment of cancer as angiogenesis inhibitors. Clinical studies suggest a significant mortality reduction in cancer patients receiving different heparin fractions for the treatment of venous thromboembolism versus those receiving UFH (Akl et al., 2008). However, conflicting data have been presented in different clinical studies and at present there is not approved use of LMWH for survival gain in cancer patients without a need for venous thromboembolism prophylaxis or treatment (Kakkar, 2004; Kwaan et al., 2009; Mousa \& Petersen, 2009; Norrby, 2006; Sideras 
et al., 2006; Thodiyil \& Kakkar, 2002). Therefore, the potential role of LMWH heparin requires additional clinical evaluation. In particular, these studies should focus on identifying which type and stage of cancer that are most likely to respond to this form of therapy, as well as on optimizing the dose and duration of treatment (Robert, 2010).

As mentioned in the introduction, angiogenesis is a complex multistep process involving activation, proliferation and migration of endothelial cells, degradation of ECM by proteolytic enzymes (e.g. heparanase) and formation of the capillary vessel lumen (Marchetti et al., 2008). Moreover, tissue factor (TF) and its natural inhibitor (TFPI) are also important heparin-binding proteins that perform well-recognized roles in the regulation of angiogenesis, tumor growth and metastasis (Bobek \& Kobarik, 2004; Borsig, 2010; Debergh et al., 2010; Norrby, 2006). LMWH may influence angiogenesis through modulation of the expression of angiogenic growth factors (VEGF and bFGF) and their inhibitors (Dogan et al., 2011; Gasowska et al., 2009; Mousa \& Petersen, 2009).

LMWH can be classified according to their molecular weight into first generation and second generation, as show in table 1 (Hirsh et al., 2001; Vignoli et al., 2011).

\subsubsection{First generation heparins}

First generation LMWH present an average molecular weight between 4 and $6 \mathrm{kDa}$ and both antiangiogenic and anticoagulant properties (Hirsh et al., 2001; Mousa \& Petersen, 2009; Vignoli et al., 2011). Representative examples are dalteparin, tinzaparin, enoxaparin, nadroparin and other heparin fractions in the range of this mean molecular weight. In addition to differences in average molecular sizes, these LMWH differ on sulfation density and distribution of the sulfate groups along the macromolecular chains due to the manufacturing process. These differences influence to their antiangiogenic potentials and the possible anticancer mechanism (Norrby, 2006).

The main mechanism underling the antiangiogenic effect of the LMWHs is based on their interaction with the heparin-binding site of VEGF and bFGF and the subsequent inhibition of their cellular receptors (VEGFR and FGFR) (Bobek \& Kovarik, 2004; Debergh et al., 2010; Gasowska et al., 2009; Mousa \& Petersen, 2009).

Norrby and Nordenhem investigated if dalteparin (Fragmin, 6kDa), epirubicin as an important chemotherapeutic agent or a combination of these two drugs modulated angiogenesis in vivo by rat mesentery assay (Norrby \& Nordenhem, 2010). Heparins were administrated by subcutaneous infusion at different concentration during 14 days. In these conditions, the effects on VEGF-mediated angiogenesis were measured. Dalteparin significantly stimulated angiogenesis in an inversely dose-dependent manner. The lowest concentration of $27 \mathrm{IU} / \mathrm{kg} /$ day produced the maximum increase the microvascular length (MVL) by $25 \%$ and total microvascular length (TMVL) by $71 \%$. On the other hand, epirubicin did not significantly affect angiogenesis. However, concurrent treatment with the two drugs significantly inhibited angiogenesis. Particularly, the MVL decreased by $24 \%$ and the TMVL by $45 \%$, using injection of epirubicin at $3 \mathrm{mg} / \mathrm{kg} /$ week and dalteparin at $80 \mathrm{IU} / \mathrm{kg} /$ day. This appears to be the first demonstration that LMWH in its own is able to increase angiogenesis in vivo. Recently, it was reported that UFH and dalteparin exerted similar effects on angiogenesis using the Matrigel plug assay in mice (Takahashi et al., 2005). On the other hand, Marchetti et al. studied how LMWHs affected the angiogenic potential of human microvascular endothelial cells (hMVEC) promoted by different tumor cells as well as growth factors (VEGF and FGF-2). Dalteparin, and enoxaparin (Clexane, $4.5 \mathrm{kDa}$ ) were 
selected on the basis of their different molecular weight range and manufacture process, as these characteristics are thought to affect their pharmacokinetic and biological properties (Hirsh et al., 2001). The angiogenesis inhibition was evaluated by in vitro capillary-like tube formation assay in Matrigel. The results demonstrated both LMWHs significantly inhibited microvascular endothelial cells capillary-like tube formation when induced by human breast cancer and leukemia cells, while a lower inhibitory effect was observed with UFH $(100 \%$ inhibited by enoxaparin, $70-90 \%$ by dalteparin and only $25-33 \%$ by UHF, depending on the considered growth factor). These results indicated that these heparins played an important role in VEGF mediated capillary formation (Marchetti et al., 2008).

Recent clinical studies have shown the effect of dalteparin in the treatment of patients with cancer. In the Fragmin Advanced Malignancy Outcome Study (FAMOUS) 385 patients with advanced solid tumor malignancy were randomly assigned either a once-daily subcutaneous injection of the dalteparin in a dose of 5000 units or placebo for 1 year. The study demonstrated a 5\% survival advantage at 1 year in favour of the advanced cancer patients who received dalteparin. These findings have been further confirmed in other clinical trials (Bick, 2006; Kakkar, 2004; Kakkar et al., 2004; Kwaan et al., 2009).

The differential effects of LMWHs compared to UFH on angiogenesis seem to be depending on the size of the molecule and number of saccharide units. It has been shown that LMWH, in contrast to UFH, can reduce binding of growth factors to their receptors. Based on these findings, the lower mean molecular weight of enoxaparin compared to dalteparin should be responsible for the higher inhibitory effect of capillary tube formation (Khorana et al., 2003; Marchetti et al., 2008).

Similarly, Khorana et al. demonstrated that molecules with a molecular weight in the range of 3-6 kDa or more than 8 saccharide units maximally inhibited angiogenesis in a Matrigel assay using human umbilical vein endothelial cells (HUVECs). Specifically, fraction of 6 and $3 \mathrm{kDa}$ inhibited FGF-proliferation by 94 and 60\%, respectively. However, the measure of heparin fractions of lower molecular weight, as $2.4,1.7$ and $1.2 \mathrm{kDa}$, showed no significantly inhibition of proliferation. Moreover, the time of action and the concentration of heparin fraction were optimized, determining that the maximum capacity inhibition of $6 \mathrm{kDa}$ fraction was at 72 hours and $5 \mu \mathrm{g} / \mathrm{ml}$.

On the other hand, the results showed that heparins fractions with the same range of molecular weight also reduced tube formation through the organization into tubular structures ( 3 and $6 \mathrm{kDa}$ heparin fractions decreased the formation of capillary-like tube structures between 58 and $78 \%$, respectively). Chain length and molecular weight significantly affect other functional properties such as bioavailability after subcutaneous administration, half-life, binding proteins or anticoagulant activities.

Norrby et al. studied the effect of heparin fractions on the microcapillary sprouting in angiogenesis mediated by VEGF using a rat mesenteric window assay. Heparin fragments with molecular weight of 2.5 to $5 \mathrm{kDa}$ reduced the number of microvessel and branching points per unit tissue volume more effectively than $16.4 \mathrm{kDa}$ fraction (Norrby, 2000). On the other hand, FGF-mediated angiogenesis was more intensely suppressed by $2.6 \mathrm{kDa}$ fraction compared with 4 fractions of higher molecular weight. The heparins fraction in this study varied in charge density and anticoagulant activity (Khorana et al., 2003). In this sense, it is important to emphasize that the anticoagulant properties of heparins are related to chain length, as reflected by the increased anti-Xa/anti-Ila activity of LMWHs (Figure 3) (Bobek \& Kovarik, 2004; Grande \& Caparro, 2005; Hirsh et al., 2001). Other authors demonstrated that 
heparin fragments with less than 18 saccharides hinder the activity of VEGF and those with less than 10 saccharides reduce bFGF activity (Bobek \& Kovarik, 2004; Debergh et al., 2010; Dogan et al., 2011).

Debergh et al. studied the effects of nadroparin (Fraxiparin, $4.5 \mathrm{kDa}$ ) on tumor-associated angiogenesis, using a dorsal skinfold window chamber model in the Syrian hamster. Active angiogenesis was observed in control animals, however nadroparin inhibited tumorassociated angiogenesis and normalized microvessel structure in this immunocompetent tumor model (Debergh et al., 2010).

Klerk et al. evaluated the effect of nadroparin on survival in patients with advanced malignancy based on time from random assignment to death. At 6 months the survival was $61 \%$ in the nadroparin group versus $56 \%$ in the placebo group indicating that a brief 6 -week course of subcutaneous nadroparin favourably influences the survival in patients with advanced solid malignancy (Klerk et al., 2005; Kwaan et al., 2009).

It is important to consider that angiogenesis is a multi-step process. Tumoral cells activate blood coagulation involving procoagulant factors, such as the tissue factor (TF). TFPI is a natural inhibitor of this procoagulant factor that suppresses a number of steps in the angiogenic process. TFPI is a heparin-binding protein. Particularly, LMWH suppress the activity of the TF and release of TFPI which appear to inhibit tumor growth (Amirkhosravi et al., 2003; Bobek \& Kovarik, 2004; Gasowska et al., 2009; Kuczka et al., 2009; Mousa \& Petersen, 2009; Vignoli et al., 2006). Recent studies demonstrated that the inhibition of angiogenesis through the TFPI release is dependent on the molecular size of the heparin used. Tinzaparin (Innohep, $6.5 \mathrm{kDa}$ ) is especially effective at releasing TFPI (Amirkhosravi et al., 2003; Hirsh et al., 2001). Preclinical in vitro studies have shown that the higher the molecular weight and degree of sulfation of tinzaparin fractions, the higher the angiogenesis inhibition by control of TFPI (Mousa \& Mohamed, 2004b; Mousa \& Petersen, 2009; Norrby, 2006).

Several trials have confirmed clinical efficacy and tolerability of tinzaparin, including in cancer patients where tinzaparin was found more effective and as safe as warfarin (a commonly used anticoagulant) for long-term treatment (Kwaan et al., 2009). Amirkohsravi et al. investigated the effect of tinzaparin on long metastasis using a B16 melanoma model in experimental mice. The results indicated that administration of tinzaparin strongly inhibits tumor-associated coagulopathy and experimental metastasis. In particular, the injection of $10 \mathrm{mg} / \mathrm{kg}$ of tinzaparin significantly decreased the number of lung tumor modules from 30 with controls to only 3 . Additionally, a second injection of the same dose of heparin during 14 days reduced the tumor mass by $96 \%$. The favorable pharmacokinetic attributed to this agent compared to UFH, together with its superior ability to release TFPI for relatively long periods from vascular endothelial cells, provide a rationale for its use in oncology as a metastatic as well as an antiangiogenic agent (Amirkhosravi et al., 2003). As TF is involved in tumor angiogenesis through the regulation of VEGF expression, it could be hypothesized that heparins can interfere with the angiogenic process through TF downregulation as well (Debergh et al., 2010; Kuczka et al., 2009; Marchetti et al., 2008; Mousa \& Petersen, 2009; Vignoli et al., 2006).

Other important first generation heparins are certoparin (6.0 kDa) (Kwaan et al., 2009; Norrby, 2006) and reviparin (Clivarine, $4.5 \mathrm{kDa}$ ) (Hirsh et al., 2001; Norrby, 2006). Tempelhoff et al. studied whether cancer mortality in women with previously untreated breast and pelvic cancer is reduced in those who randomly received certoparin compared to 
patients treated with UFH. Survival in the patients with certoparin treatment was significantly improved after 650 days for pelvic cancer. Particularly, the mortality rate was $9 \%$ in the certoparin group versus $29 \%$ in the patients with UFH treatment (Von Tempelhoff et al., 2000).

Pross et al. studied the influence of reviparin at different concentration $(0.55,1.10$ and 2.76 $\mathrm{mg} / \mathrm{ml}$ ) on the intraabdominal tumor growth through in vitro Matrigel assay and in vivo experiments with rats. After application of reviparin, an important inhibition of tumor cells adhesion was observed, particularly with the highest concentration used (1.6 $10^{5}$ cells were measured in the control group, whereas the number of cells were $0.36 \cdot 10^{5}$ with the reviparin). Moreover, the invasive potential was reduced to more than $50 \%$ for all concentrations of heparin. On the other hand, a combination of peritoneal and subcutaneous administration of reviparin reduced tumor growth in rats to higher concentrations of $4 \mathrm{mg} / \mathrm{ml}$ (Mousa \& Petersen, 2009; Norrby, 2006; Pross et al., 2003).

Collen et al. evaluated the effects of reviparin and UFH on growth factor-induced proliferation and the formation of capillary-like tubular structures by hMVEC. Reviparin inhibited the proliferation of hMVEC induced by angiogenic factors bFGF and VEGF and affected fibrin matrix formation. Particularly, reviparin enabled the formation of more rigid and fine fibrin fibers, whereas UFH caused the formation of thick and porous fibers. These results may indicate a novel mechanism by which LMWHs affect tumor angiogenesis. However, contradictory results have been described in recent studies (Bobek \& Kovarik, 2004; Collen et al., 2000; Gasowska et al., 2009; Norrby, 2006).

\subsubsection{Second generation heparins}

Recently, the second generation LMWHs is being investigated. These new generation of heparins are characterized by a lower mean molecular weight, a more precisely defined composition of polysaccharidic chains and better anti-Xa/anti-Ila ratio. The first generation LMWHs had between 25 and $50 \%$ of fragments with 18 or more saccharides. However, the new generation of heparins contains a significant lower percentage of long chains, improving their therapeutic action and reduce the problems of coagulation and bleeding. Moreover, these properties may lead to a more favorable behavior as regards the efficacy / safety ratio. The comparison of the properties of first and second generation heparins is shown in Figure 3 (Norrby, 2006).
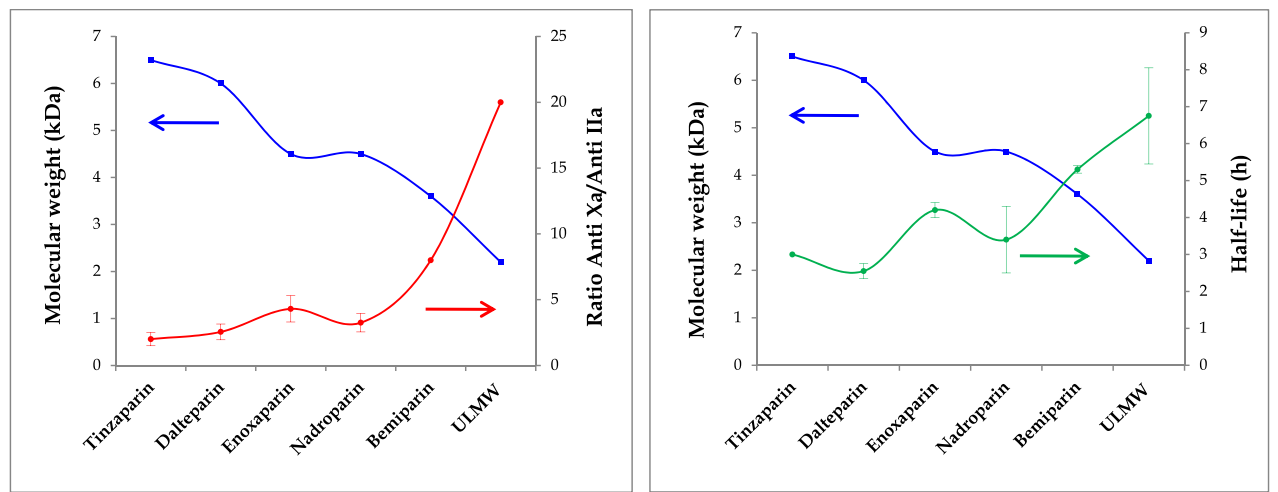

Fig. 3. Molecular weight vs antiXa/antiIIa ratio and molecular weight vs half-life. 
Bemiparin (Badyket, $3.5 \mathrm{kDa}$ ) (Balibrea et al., 2007; Dogan et al., 2011; Jeske et al., 2011; Vignoli et al., 2011) has been available in Europe for 10 years but only recently has been evaluated in clinical trials to determine its angionenic potential in patients with cancer. The efficacy of bemiparin administration in patients limited small cell lung cancer was evaluated in the ABEL study. Randomized patients received homogeneous treatment with chemotherapy or standard treatment plus bemiparin during 26 weeks. The administration of bemiparin significantly improved the clinical outcome in patients with cancer. Particularly, after several months of treatment, $77 \%$ of the bemiparin group patients were alive compared to $20 \%$ of the control group. Moreover, significant survival advantages have been demonstrated when this molecule was co-administrated with chemotherapeutic agents.

Ultralow molecular weight heparins (ULMWH), such as $R O-14,(2.2 \mathrm{kDa})$ are currently in clinical developmental phase. The aim of these early studies is to evaluate the safety and pharmacodynamic profile of ULMWH. Rico et al. conducted a complete randomized study with two cohorts of volunteers to determine the pharmacodynamic properties of RO-14. The results indicated that RO-14 has a good anti-Xa activity (80-140 IU/mg), a higher half-life than other marketed LMWH (between 5 and 8 hours compared with $2-4$ hours for dalteparin, enoxaparin or tinzaparin) and is characterized by its non-anti-Ila activity $(<10$ $\mathrm{IU} / \mathrm{mg}$ versus $58 \mathrm{IU} / \mathrm{mg}$ of dalteparin, for example) (Rico et al., 2011).

Since the antiangiogenic properties of heparin fractions depend on the average molecular weight and the composition of their polysaccharidic chains, it is necessary to evaluate the angiogenesis effect of the second generation heparins. According to recent studies, bemiparin and RO-14 appear to be effective in preventing and inhibiting angiogenesis in in vitro assays (Bosch et al., 2010).

Vignoli et al. determined the angiogenesis inhibition of the bemiparin and RO-14 by in vitro capillary-like tube formation assay in Matrigel. The experiments were performed using tumor-cell-conditioned media (TCM) from different tumor cell lines as well as growth factors (VEGF and FGF-2). In these conditions, heparins decreased tube formation induced by TCM, between $82-100 \%$ at $10 \mathrm{IU} /$ depending on the tumor cell line used. Moreover, capillary-like tube formation induced by growth factors was $100 \%$ inhibited at the highest concentration of heparin used. These complete results indicate a possible role of these molecules as adjuvant drugs in cancer treatment and suggest that the antiangiogenic inhibition can be remained by heparins with a lower molecular weight and shorter polysaccharidic chains (Vignoli et al., 2010; Vignoli et al., 2007; Vignoli et al., 2011).

Different authors have shown that bemiparin increases the release and activity of TFPI from endothelial cells (Planès, 2003; Sánchez-Ferrer, 2010; Vignoli et al., 2011). In addition, recent studies have demonstrated that bemiparin has a better control over this factor compared to UFH and first generation heparins such as dalteparin. (Perez-Ruiz et al., 2002; Westmuckett et al., 2001)

Westmuckett et al. studied the release and expression of TFPI in endothelial cells under static conditions and arterial sheer stress with the therapeutic action of bemiparin compared with dalteparin and UFH. In all experiments, bemiparin showed the most important cellular TFPI activity. On the other hand, the three types of heparin enhanced the expression of TFPI by 60 to $120 \%$ under static conditions and this increase only was possible with bemiparin under arterial stress. Perez-Ruiz et al. compared the TF activity of bemiparin and UFH using human umbilical vein endothelial cells (HUVEC). Samples were prepared with the addition 
of heparins at 1 or $10 \mathrm{IU} / \mathrm{ml}$ and measured after 2, 6, and 24 hours. Only both concentrations of UFH produced a significant enhance of TF expression.

However, conflicting data have been presented in different studies. Depasse et al. studied the TFPI release profiles of bemiparin and tinzaparin through their subcutaneous administration to randomized volunteers. These parameters were performed by using ELISA total and free TFPI kits. The results indicated that bemiparin experimented more rapid and potent antithrombotic (antiXa) activity but the TFPI release was significantly lower than with tinziparin. Particularly, the mean maximum free TFPI was $70 \mathrm{ng} / \mathrm{ml}$ after the injection of tinzaparin but only $30 \mathrm{ng} / \mathrm{ml}$ in the case of bemiparin. The differences in the average molecular weight and sulfation degree may influence these behaviours (Depasse et al., 2003). Recent studies compare the angiogenic effect of the bemiparin with others first generation LMWH in the chick embryo chorioallantoic membrane (CAM) model. This in vivo study used different concentrations of heparins $(1,10$, and $100 \mathrm{IU} / 10 \mu \mathrm{l})$ and measured the decrease of vessel formation using stereoscopic microscope. The results demonstrated that bemiparin, enoxaparin, nadroparin and tinzaparin have antiangiogenic effects on CAM, being more significant in high concentrations (100 IU/10 $\mu \mathrm{l})$. Moreover, nadroparin and tinzaparin have also substantial antiangiogenic effects at the moderate concentration of 10 $\mathrm{IU} / 10 \mu \mathrm{l}$ as a result of their higher antiangiogenic potential. A possible categorization of LMWHs in this context would facilitate the choice of drug that would be used in further experimental and clinical research (Dogan et al., 2011).

Actually, new ULMWHs are investigated as semuloparin $(2.5 \mathrm{kDa})$ with a half-life of $16-20$ hours that allows one daily subcutaneous injection. It is produced using a novel depolymerization reaction with high selectivity. Jeske et al. compared the biological activity of semuloparin and bemiparin through coagulation and pharmacological assays. The results of this study indicated that the differences in the oligosaccharide composition and manufacturing process may influence biological activity such as protein interactions with growth factors. Moreover, these differences may translate into a different clinical safetyefficacy profile (Jeske et al., 2011).

\subsection{Chemically modified heparins}

Chemical modification of heparin has become a potent strategy to obtain new compounds with different biological properties from the original GAG. This is possible because of the presence of multiple functional groups susceptible of chemical modification. Heparin is a linear, polysulfated and polydispersed polysaccharide composed of $\beta$-D-glucopyranosiduronic acid (glucuronic acid, GlnA) or $\alpha$-L-idopyranosiduronic acid (iduronic acid, IdoA) and $N$ acetyl or $N$-sulfo D-glucosamine $(\mathrm{GlcN})$ with a $(1 \rightarrow 4)$ linkage. These residues are variably substituted with anionic $\mathrm{O}$-sulfo (sulfate) and $\mathrm{N}$-sulfo (sulfoamino) groups giving the GAG a highly negatively charge (-2.7 sulfo groups / disaccharide) (Figure 4$)$.

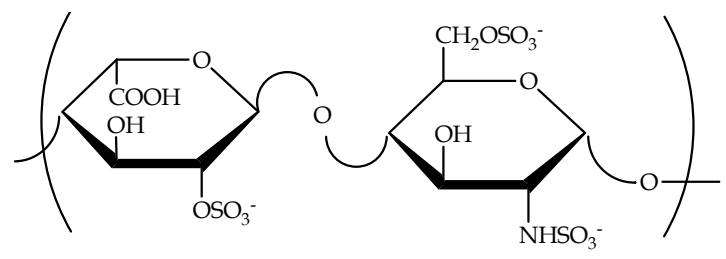

Fig. 4. Chemical structure of heparin. 
Most of the attempts to modulate protein binding and biological properties of heparin have been made by the modulation of the sulfation patterns of the GAG backbone and enhance of chain flexibility of the GAG by the glycol-splitting of C2-C3 bonds of nonsulfated GlcA and IdoA residues. Both the degree of sulfation (charge density) and the appropriate distribution of $\mathrm{N}$-sulfate and $\mathrm{N}$-acetyl groups (charge distribution) along the heparin molecule is determinant in its biological properties. For example, the strongest protein binding was observed for 'fully sulfated' heparin and extra-sulfate groups potentiated this interaction.

Chain flexibility is thought to play a key role in heparin-protein interactions. It is conferred by IdoA-containing sequences which are considered to facilitate the appropriate orientation of substituents for the suitable interaction (Casu et al., 2002a; Casu et al., 2002b). Additional local flexibility was obtained by glycol-splitting that act as flexible joints along the heparin chain were conformation changes can be induced by the protein interaction.

Chemical modifications of heparin have been reviewed in depth by Casu et al. (Casu et al., 2002b) and Fernandez et al. (Fernández et al., 2006) that described the biological effect of $N$ sulfate removal, $\mathrm{N}$-acylation of native amino groups or amino groups created after $\mathrm{N}$ desulfation, $\mathrm{O}$-sulfate removal, sulfation of hydroxyl groups (existing in the molecule or exposed by desulfation), acylation of unsubstituted hydroxyl groups and glycol-splitting.

Several groups have dedicated their research activity of the last decades to understand the structure-activity relationship of this molecule by its controlled chemical modification. One of the most interesting chemically modified heparins was developed by Nagi et al. (Naggi et al., 2005) SST0001 (= 100NA-RO.H = HI2), a 100\% N-acetylated and 25\% glycol-split modified heparin (Figure 5), inhibits heparanase and presents non-anticoagulant activity and the ability to inhibit metastasis formation in various metastatic tumor animal models and activity also in human multiple myeloma models (Ritchie et al., 2011).

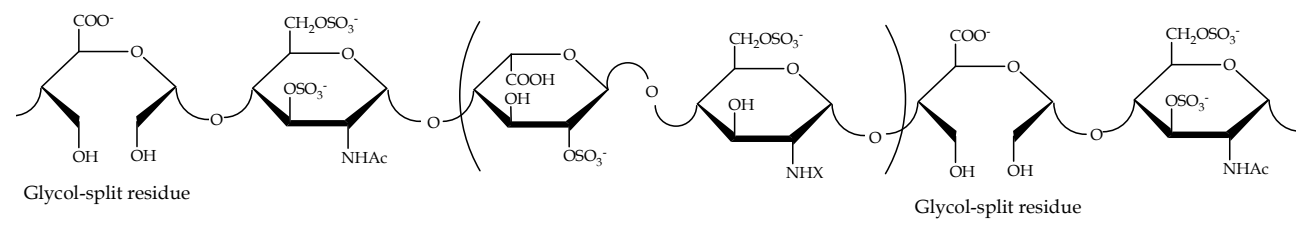

Fig. 5. Chemical structure of SST0001 (= 100NA-RO.H = HI2), a 100\% N-acetylated and 25\% glycol-split heparin. Heparin was $N$-acetylated by time-controlled $N$-desulfation under solvolytic conditions. Glycol-split $N$-acetylated heparin was prepared by exhaustive periodate oxidation and borohydride reduction of the resulting dialdehydes.

Heparanase inhibition decreases heparin-binding growth factor release (FGF, VEGF) from ECM via HPGS degradation inhibiting the angiogenesis activity induced by these GF. Glycol-splitting causes heparin to lose affinity for antithrombin (GlcA residue in the pentasaccharide sequence of the active site for antithrombin is modified) and therefore a non-anticoagulant activity. The combination of heparanase inhibition, inhibition of ECMbound proangiogenic growth factors release and the non-anticoagulant activity points SST0001 as potential antiangiogenic and antimetastatic agent.

Another heparinoid with negligible anticoagulant activity is ST2184 obtained by controlled nitrous acid depolymerization of undersulfated glicol-split ST1514 (Pisano et al., 2005). 


\subsection{Heparin-conjugates}

Heparin has been conjugated to different molecules in order to obtain new drug delivery systems and scaffolds for tissue engineering with controlled angiogenic properties. In this sense, heparin has been conjugated to chemotherapeutic agents (e.g. paclitaxel), hydrophobic moieties (e.g. $N$-deoxycholyethylenediamine), thermosensitive polymers (e.g. Poloxamers) or even proteins (e.g. antithrombin or endostatin) in order to improve drug availability, drug targeting, heparin stability or modulate anticoagulant behaviour and angiogenic properties.

Paclitaxel is a widely used chemotherapeutic agent for the treatment of solid carcinomas. However, its clinical use is limited by its poor aqueous solubility. Several authors have been working in the preparation of new paclitaxel-heparin delivery systems with improved chemotherapy efficacy and enhanced antiangiogenic activity. In this sense, Wang et al. prepared amphiphilic heparin-paclitaxel prodrugs by covalent conjugation through hydrolysable bonds based on a single aminoacid spacer, either valine, leucine or phenylalanine (Y. Wang et al., 2009a; Y. Wang et al., 2009b). Heparin (hydrophilic)-paclitaxel (hydrophobic) system spontaneously self-assembled in aqueous solution forming nanoparticles with appropriate properties for drug delivery applications. These materials preserved structural integrity of paclitaxel, presented appropriate drug delivery profiles and also enhanced targeting capacity to solid tumors. Park et al. followed a similar strategy and conjugated heparin with paclitaxel through an amide linkage and observed comparable results (I.K. Park et al., 2010b).

A ternary conjugate heparin-folic acid-paclitaxel, loaded with additional paclitaxel, was developed to specifically target folate receptor that is highly expressed in several types of solid tumors, including ovarian, uterine, lung, breast, and head and neck cancers (X. Wang et al., 2009). Other ternary system that included folate has been recently developed: succinylated heparin conjugated with folate via polyethylene glycol (PEG) 1000/3000 spacers (Wang et al., 2010) or heparin-retinoic acid-folic acid conjugates (I.K. Park et al., 2010a). These systems displayed amphiphilic properties and formed nanoparticles capable of entrapping hydrophobic agents, such as taxol.

$\mathrm{N}$-deoxycholyethylenediamine (DOCA) was covalently attached to the carboxylic acids of heparin (Park et al., 2007) or LMWH Fraxiparin (D.Y. Lee et al., 2009; J.W. Park et al., 2010) via amide formation resulting in an amphiphilic system. Heparin-DOCA derivatives presented lower anticoagulant activity, but inhibited angiogenesis both in vitro and in mice model and were postulated as promising drug carriers due to its amphiphilic structure. Moreover, LMWH-DOCA (D.Y. Lee et al., 2009) systems were successfully designed to be orally absorbed improving their therapeutical potential, due to DOCA (hydrophobic) enhanced the interaction between heparin and the intestinal membrane. Fraxiparin was also conjugated with taurocholate giving rise to helical-structured macromolecules with strong antiangiogenic activity and significant tumor growth inhibition potencial on SCC7 and MDA-MB231 human breast carcinoma cells subcutaneously injected in mice (E. Lee et al., 2009).

Tan et al. prepared LMWH-endostatin conjugates in order to obtain a synergistic effect of both endostatin (a potent endogenous angiogenesis inhibitor) and LMWH, so better antiangiogenesis and antitumor activity of the modified products was observed in vitro (Tan et al., 2008) and in vivo using the CAM assay, corneal neovascularization (CNV) assay and $\mathrm{S}_{180}$ tumor bearing mice (Tan et al., 2011). LMWH not only acted as a good protein modifier (the conjugates presented enhanced heat stability than endostatin, high percentage of 
retained activity and slight secondary structure alteration), but also played an active role in the biological activity of the resulting product.

Heparin-poloxamer-heparin conjugates were also developed giving rise to self-assembled nanoparticles with marked thermosensitivity for drug delivery (Chung et al., 2010; Tian et al., 2010).

Latent antithrombin was covalently attached to heparin and both the anticoagulant behaviour and antiangiogenic activity of the conjugate studied for its application in the treatment of the respiratory distress syndrome (Parmar et al., 2009). The conjugate exerted a selective antiproliferative effect on lung fibroblasts and the antiangiogenic effect of latent antithrombin was prevented when permanently bound to heparin. Anticoagulant activity of antithrombin was not significantly affected by the chemical modification.

\subsection{Biotechnological heparins}

Heparin is a heterogeneous mixture of molecules isolated from animal tissues, historically from bovine tissues and currently mostly from porcine tissues. Animal-derived pharmaceutical products represent a high risk to humans due to possible animal-to-man transmitted diseases (e.g. Creutzfeldt-Jacobs syndrome) and the different chemical structure and biological effect depending on the animal source, tissue and purification procedure. Moreover, heparin is a minor component in animal tissues and its purification requires high volumes of solvents and chemicals. Therefore, new routes to obtain chemically-modified heparins in high quantities and homogeneous composition were found in biotechnology (Presta et al., 2005).

K5, a bacterial polysaccharide from Escherichia Coli, presents the same structure as heparin biosynthetic precursor and can be tailored modified by combined chemical and enzymatic approaches giving rise to a multi-target class of biotechnological heparin/HS-like molecules. These products present different biological properties including anticoagulant/ antithrombotic, anti-AIDS and antitumor activities (antineoplastic, antiangiogenic, and antimetastatic) depending on the performed modification (Rusnati et al., 2005).

PI88 (Progen Pharmaceuticals, http://www.progen.com.au/pipeline/angiogenesis.aspx) is a phosphosulfomannanopentaose derived from the polysaccharide secreted by the yeast $P$. Holstii (Parish et al., 1999) that not only inhibits heparanase and stimulates TFPI release, but also interferes with heparin-binding growth factors inhibiting angiogenesis and metastasis. PI88 is currently being evaluated in multiple phase II clinical trials for the treatment of lung cancer (NSCLC), primary liver cancer, multiple myeloma and melanoma.

\subsection{Synthetic sulfated oligosaccharides}

Synthetic oligosaccharides are also under investigation as heparin-like compounds with antiangiogenic activity.

Progen Pharmaceuticals has also developed PG500 a series of fully synthetic and fully sulfated family of single entity oligosaccharides attached to a lipophilic moiety (aglycone) at the reducing end of the molecule. These compounds inhibit FGF-1, FGF-2 and VEGF and also heparanase (Dredge et al., 2010).

Borsig et al. described the heparanase and selectin inhibitory effect of novel semisynthetic sulfated trimannose C-C-linked dimmers. These sulfated hexasaccharides mimic maltohexaose sulfate, a potent carbohydrate-based heparanase inhibitor currently subjected to phase II/III clinical trials in cancer patients (Borsig et al., 2011). 


\section{Synthetic heparin-like compounds}

The polysulfated character of heparin suggests that polymers carring sulfonic groups could be a good strategy to sinthesize new antiangiogenic drugs.

The evolution of heparin-like synthetic drugs started in the early 90's. A polysulfonated naphthylurea (Suramin) was investigated in the inhibition of different proangiogenic factors (Danesi et al., 1993; Gagliardi et al., 1992). Based on the structure of suramin, different polysulfated and polysulfonic acid polymers were developed with capacity to interact with proangiogenic factors in similar mode to heparin (Fernández-Tornero et al., 2003; Liekens et al., 1999; Liekens et al., 1997). Actually there are different polyanionic and nonpolysulfonated components under study with capacity to interact with proangiogenic factor in the same binding-site that HSPGs (Fernández et al., 2010).

\subsection{Polysulfated/polysulfonated heparin-like compounds}

The mechanism of action of these heparin-like drugs is based on its similarity with heparin structure. The sulfate groups of these compounds interact with different heparin-binding angiogenic factors in a similar way to heparin and inactivate it thereby preventing induction of angiogenesis.

\subsubsection{Suramin}

Suramin is a polysulfonated naphthylurea and an antitrypanosomal agent used since the early 1920s for the treatment of onchocerciasis and African sleeping sickness (Williamson, 1957; Williamson \& Desowitz, 1956). In the early 90's suramin was investigated in the inhibition of different growth factors due to its similarity with heparin. Different researchers demonstrated the antagonism character between heparin and suramin and the capacity to inhibit different angiogenic factors by preventing their interaction with cell-surface HSPGs (Danesi et al., 1993; Gagliardi et al., 1992). This activity is due to the capacity of suramin to bind to the heparin-binding site of the proangiogenic factors via the sulfonate groups (Braddock et al., 1994; Middaugh et al., 1992).

Suramin was employed in the treatment of conventional chemotherapy unresponsive tumors (Hawkins, 1995), however high doses were necessary to achieve anti-tumor activity which developed intolerable toxicities (Collins et al., 1986; Constantopoulos et al., 1983).

In order to improve the activity of suramins and decrease its toxic-side effects, different polysulfonated naphthylureas structurally related to suramin were investigated. The results demonstrated that modifications in the backbone and the number of sufonic groups had a significant effect on angiogenesis inhibition (Manetti et al., 1998; Zamai et al., 1998). All the suramin derivatives contain the amido- $N$-methylpyrrolnaphthalenesulfonic acid group and are generally called suradistas.

Suradistas present a higher inhibition of bFGF-induced mitogenesis on fibroblasts and a higher inhibition of the neovascularization of the CAM than suramins (Hassan, 2007).

\subsubsection{Pentosan polysulfate}

Pentosan polysulfate (PPS) is a semi-synthetic pentasaccharide heparinoid derived from beech wood shavings. Its activity is also due to the presence of sulfonic groups that interact with different heparin-binding growth factors (Zugmaier et al., 1992). PPS has demonstrated inhibition of endothelial cell motility, tubule formation in vitro and capillary formation in in vivo assay (Nguyen et al., 1993). 
PPS has been evaluated in the inhibition of cancer and Kaposi's sarcoma in vitro (Nakamura et al., 1992) and, also, in clinical trials phase I/II (Lush et al., 1996), but its clinical application has been limited by the high anti-coagulant activity at doses needed to inhibit the angiogenesis.

\subsubsection{1,3,6-Naphthalenetrisulfonic acid}

In order to decrease the toxic side-effects of suramin, different derivatives of these compounds were studied in the last years. Lozano et al. demonstrated that 1,3,6naphthalenetrisulfonic acid (NTS) seem the active part of suramin (Lozano et al., 1998). In their studies showed that NTS is an effective inhibitor of the mitogenic activity of aFGF and this activity is due to the interaction with aFGF in the heparin binding-site.

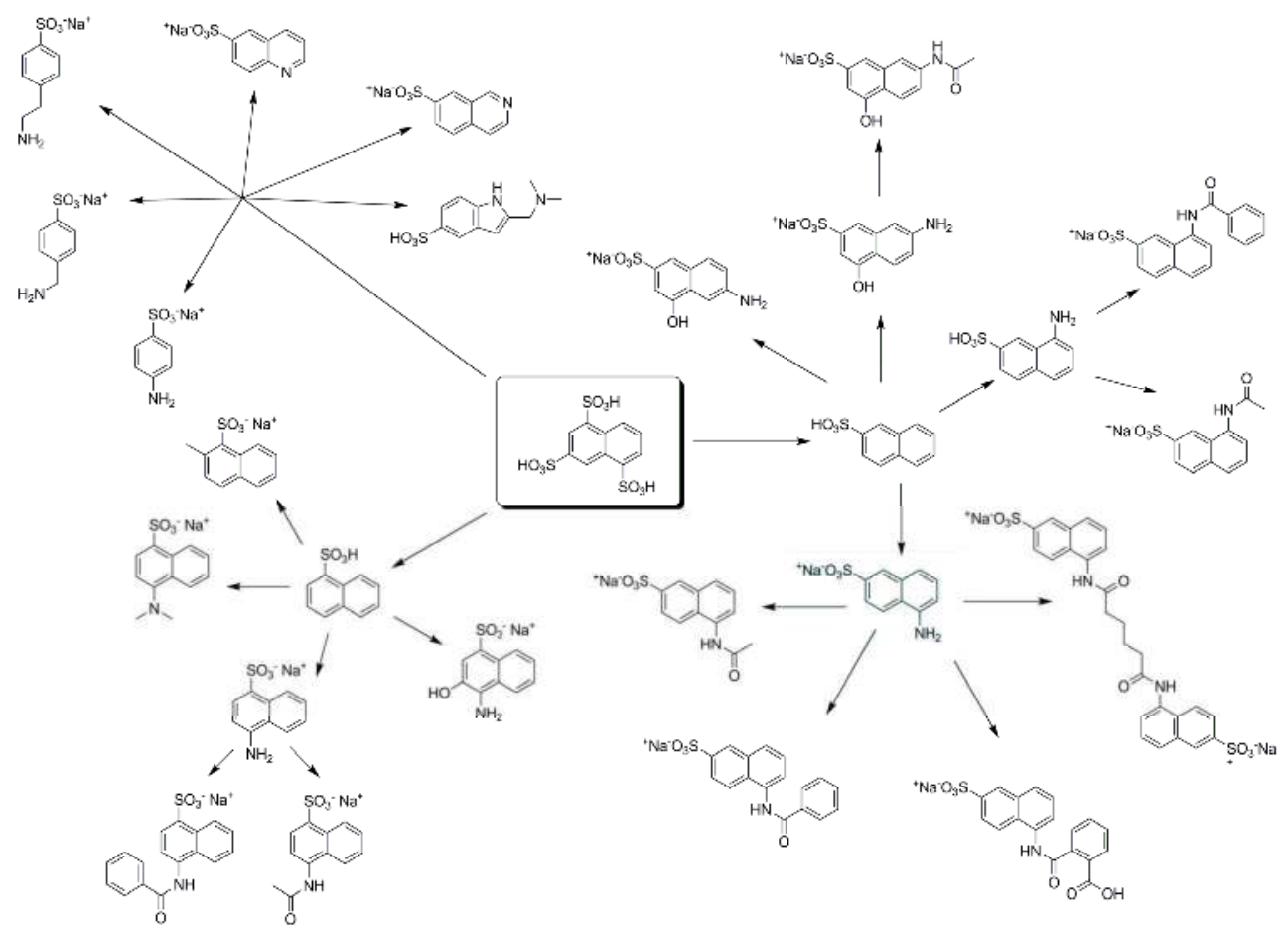

Fig. 6. NTS-based compounds studied by Fernández-Tornero et al.

The union of NTS to aFGF causes a displacement in the aminoacids and creates a cavity in the surface of NTS-bound aFGF. This cavity increases the solvent accessibility of this inner core and stabilizes the molecule, in this conformation the aFGF become inactive to activate the angiogenic process.

In the last years, Fernández Tornero et al. studied different compound derived from NTS with different numbers of sulfonic groups and substituents (Figure 6) (Fernández-Tornero et al., 2003).

5-amino-2-naphthalenesulfonic acid (ANSA) showed the best antiangiogenic activity and lower toxicity. The activity was related to the capacity to interact with heparin-binding site 
of FGF due to the presence of the sulfonic acid group (Figure 7). In this case ANSA binds in a 1:1 stoichiometric ratio to a positively charged cavity at the surface of FGF (some of the basic residues implicated in the interaction of this protein with heparin) by the sulfonate and the amino groups. This interaction prevents the union between FGF and heparin and inhibits the activation of angiogenic process. This compound has been recently used to synthesize new sulfonic acid-bearing polymers with antiangiogenic activity (GarciaFernandez et al., 2010a; Garcia-Fernandez et al., 2010b) as described in the next section.

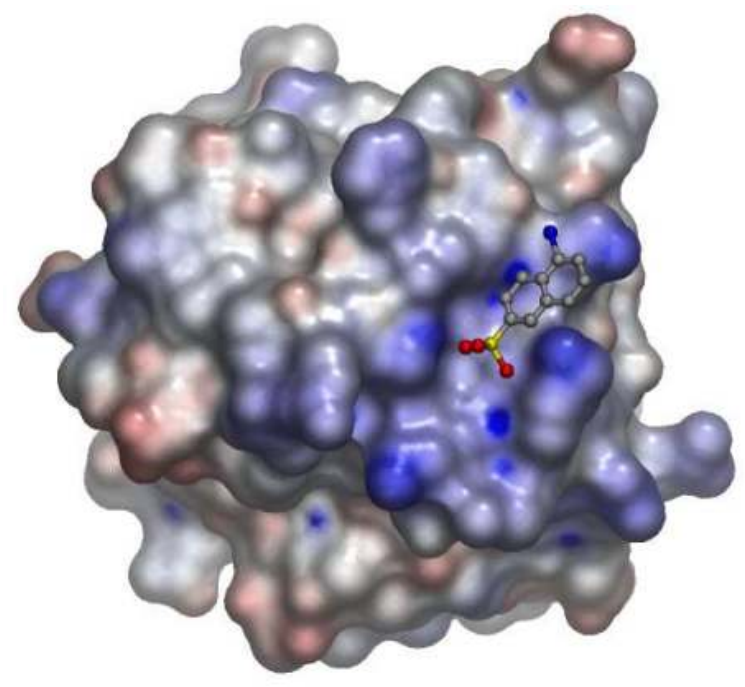

Fig. 7. A complex between acidic fibroblast growth factor and ANSA. ANSA is shown as stick-and-ball model (carbon: grey; oxygen: red; sulfur: yellow; nitrogen: blue). The figure was generated and the surfaces colored according the electrostatic potential (red, negative; blue, positive) using OpenAstexViewer (3.0; Astex Therapeutics Ltd.) and its internal parameters. PDB ID: 1HKN (Fernández-Tornero et al., 2003).

\subsubsection{Sulfonic acid polymers}

The synthesis of polymers with a heparin-like structure is a recent way to obtain polymers and copolymers with antiangiogenic activity. Liekens et al. (Bugatti et al., 2007; Liekens et al., 1999; Liekens et al., 1997) studied different sulfonic acid-bearing polymers and demonstrated their capacity to impair the binding of bFGF to HSPGs. In these studies different polymers (poly(2acrylamido-2-methyl-1-propanesulfonic acid) (polyAMPS), poly(anetholesulfonic acid) and poly(4-styrenesulfonic acid)) showed a inhibition of the aFGF-mediated mitogenic response. The highest antiangiogenic activity was obtained for polyAMPS and the study of its intereaction with FGF showed that in the polymerization each AMPS units develops several intramolecular hydrogen bonds between adjacent acrylamido units producing a helical structure similar to heparin with the sulfonate groups spaced 9-10 ̊.

In the last years García-Fernández et al. developed different families of new polysulfonic acid copolymers based on AMPS and a methacrylic derivative of ANSA (MANSA) (Garcia- 
Fernandez et al., 2010a; Garcia-Fernandez et al., 2010b; Garcia-Fernandez et al., 2010c). Two different families of copolymers with $N$-vinylpyrrolidone (hydrophilic, VP) and butylacrylate (hydrophobic, BA) were synthesised in order to obtain different properties in aqueous media. The highest antiangiogenic activity was obtained for the hydrophobic MANSA copolymers (poly(BA-co-MANSA)) due to the formation of an interesting micellar morphology by self-assembling with the hydrophilic MANSA units located on the surface of the micelle. This organization provides an optimal orientation of the sulfonic acid groups for the interaction with the growth factor. This gives an increasing inhibitory bioactivity of the poly(BA-co-MANSA) with the concentration.

\subsection{Other polyanionic compounds}

Besides the molecules described above, various non-sulfated polyanionic compounds have been investigated. For example, aurintricarboxylic acid (Figure 8) showed inhibition of heparin-stimulated angiogenesis in the CAM (Gagliardi \& Collins, 1994) or RG-13577 (a linear polymer of carboxylated phenol-based monomers) prevented microvessel outgrowth from rat aortic rings embedded in a collagen gel (Miao et al., 1997).<smiles>O=C(O)C1=CC(=C(c2ccc(O)c(C(=O)O)c2)c2ccc(O)c(C(=O)O)c2)C=CC1=O</smiles>

Aurintricarboxilic Acid<smiles>O=C(O)c1cc(O)ccc1O</smiles>

Gentisic Acid<smiles>O=C(O)Cc1cc(O)ccc1O</smiles>

Homogentisic Acid

Fig. 8. Polyanionic compounds with antiangiogenic activity (aurintricarboxylic acid, gentisic acid and homogentisic acid).

But the most promising polyanionic compounds are gentisic (a widespread plant secondary metabolite, GA) and homogentisic acid (the toxic agent in alkaptonuria, HGA) (Fernández et al., 2010) (Figure 8).

These compounds present higher antiangiogenic activity than ANSA and other sulfonic compounds both in vivo and in vitro. Both, GA and HGA bind in a 1:1 stoichiometric ratio to a positively charged cavity at the surface of FGF (part of the long cationic hearing-binding site) (Figure 9).

ANSA, GA, and HGA bind to the same site, these results were unexpected because these compounds are chemically unrelated. The relative positions of the hydroxyl groups in the aromatic ring stabilized the molecules by a network of non-covalent contacts. This inactivates FGF and blocks FGF-dependent angiogenesis. 


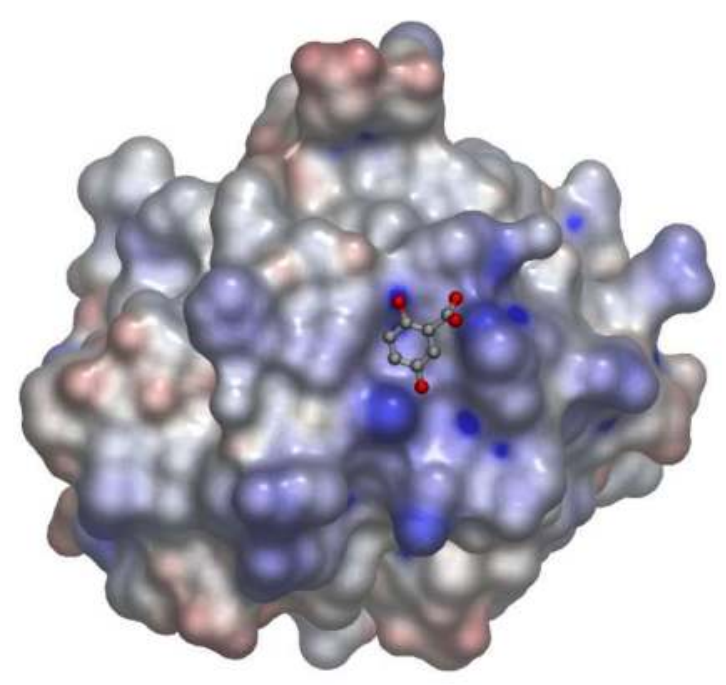

Fig. 9. A complex between acidic fibroblast growth factor and GA. GA is shown as stickand-ball model (carbon: grey; oxygen: red). The figure was generated and the surfaces colored according the electrostatic potential (red, negative; blue, positive) using OpenAstexViewer (3.0; Astex Therapeutics Ltd.) and its internal parameters. PDB ID: 3JUT (Fernández et al., 2010).

\section{Conclusions}

Heparin-like molecules that inhibit proangiogenic molecules through heparin-binding domains constitute an effective tool for the design of broad-spectrum antiangiogenic drugs. Different types of these molecules were described in this chapter, i.e. heparin species (heparinoids, chemically modified heparins, heparin conjugates, biotechnological heparins, and synthetic sulfated oligosaccharides) and synthetic heparin-like compounds. Both offer endless possibilities for the development of optimized antiangiogenic drugs using the organic chemistry procedures.

On the one hand, numerous heparin species have demonstrated their antiangiogenic activity, however it depends on a great number of factors like molecular weight, composition (saccharide units concentration), physicochemical properties (such as flexibility), charge density (degree of sulfation) and charge distribution, chemical modification, conjugated molecule, etc. Currently, for example, it is unknown which commercial LMWH and ULMWH have the greatest antiangiogenic effect in cancer patients. Therefore, systematic experimental studies of the angiogenesis-modulating effect of heparin species and comparative and complete clinical studies are needed in the future (Debergh et al., 2010; Dogan et al., 2011; Mousa \& Petersen, 2009; Norrby, 2006).

On the other hand, synthetic heparin like compounds have been developed using systematic routines in order to rationally identify the best activity/toxicity ratio. However, few of these products are currently in clinical trials and still need FDA approval. 


\section{References}

Akl, E.A., Rohilla, S., Barba, M., Sperati, F., Terrenato, I., Muti, P., Bdair, F. \& Schünemann, H.J. (2008). Anticoagulation for the initial treatment of venous thromboembolism in patients with cancer: a systematic review. Cancer, Vol. 113, No. 7, pp. 1685-1694

Alitalo, K., Tammela, T. \& Petrova, T.V. (2005). Lymphangiogenesis in development and human disease. Nature, Vol. 438, No. 7070, pp. 946-953

Amirkhosravi, A., Mousa, S.A., Amaya, M. \& Francis, J.L. (2003). Antimetastatic effect of tinzaparin, a low-molecular-weight heparin. Journal of thrombosis and haemostasis : JTH, Vol. 1, No. 9, pp. 1972-1976

Balibrea, J.L., Altimiras, J., Larruzea, I., Gómez-Outes, A., Martínez-González, J. \& Rocha, E. (2007). Optimal dosing of bemiparin as prophylaxis against venous thromboembolism in surgery for cancer: An audit of practice. International Journal of Surgery, Vol. 5, No. 2, pp. 114-119

Bick, R.L. (2006). Cancer-associated thrombosis: Focus on extended therapy with dalteparin. Journal of Supportive Oncology, Vol. 4, No. 3, pp. 115-119

Bobek, V. \& Kovarik, J. (2004). Antitumor and antimetastatic effect of warfarin and heparins. Biomedicine and Pharmacotherapy, Vol. 58, No. 4, pp. 213-219

Borsig, L. (2010). Antimetastatic activities of heparins and modified heparins. Experimental evidence. Thrombosis Research, Vol. 125, No. Supplement 2, pp. S66-S71

Borsig, L., Vlodavsky, I., Ishai-Michaeli, R., Torri, G. \& Vismara, E. (2011). Sulfated hexasaccharides attenuate metastasis by inhibition of p-selectin and heparanase. Neoplasia, Vol. 13, No. 5, pp. 445-452

Bosch, M.M., Vignoli, A., Villamediana, R.L. \& Prandoni, P. (2010). Bemiparin in oncology. Drugs, Vol. 70, No. SUPPL. 2, pp. 35-42

Braddock, P.S., Hu, D.E., Fan, T.P.D., Stratford, I.J., Harris, A.L. \& Bicknell, R. (1994). A structure-activity analysis of antagonism of the growth factor and angiogenic activity of basic fibroblast growth factor by suramin and related polyanions. British Journal of Cancer, Vol. 69, No. 5, pp. 890-898

Bugatti, A., Urbinati, C., Ravelli, C., De Clercq, E., Liekens, S. \& Rusnati, M. (2007). Heparinmimicking sulfonic acid polymers as multitarget inhibitors of human immunodeficiency virus type 1 Tat and gp120 proteins. Antimicrobial Agents and Chemotherapy, Vol. 51, No. 7, pp. 2337-2345

Casu, B., Guerrini, M., Naggi, A., Perez, M., Torri, G., Ribatti, D., Carminati, P., Giannini, G., Penco, S., Pisano, C., Belleri, M., Rusnati, M. \& Presta, M. (2002a). Short heparin sequences spaced by glycol-split uronate residues are antagonists of Fibroblast Growth Factor 2 and angiogenesis inhibitors. Biochemistry, Vol. 41, No. 33, pp. 10519-10528

Casu, B., Naggi, A. \& Torri, G. (2002b). Chemical derivatization as a strategy to study structure-activity relationships of glycosaminoglycans. Seminars in Thrombosis and Hemostasis, Vol. 28, No. 4, pp. 335-342

Collen, A., Smorenburg, S.M., Peters, E., Lupu, F., Koolwijk, P., Van Noorden, C. \& Van Hinsbergh, V.W.M. (2000). Unfractionated and low molecular weight heparin affect fibrin structure and angiogenesis in Vitro. Cancer Research, Vol. 60, No. 21, pp. 61966200 
Collins, J.M., Klecker Jr, R.W. \& Yarchoan, R. (1986). Clinical pharmacokinetics of suramin in patients with HTLV-III/LAV infection. Journal of Clinical Pharmacology, Vol. 26, No. 1, pp. 22-26

Constantopoulos, G., Rees, S., Barranger, J.A. \& Brady, R.O. (1983). Suramin-induced storage disease. Mucopolysaccharidosis. American Journal of Pathology, Vol. 113, No. 2, pp. 266-268

Coultas, L., Chawengsaksophak, K. \& Rossant, J. (2005). Endothelial cells and VEGF in vascular development. Nature, Vol. 438, No. 7070, pp. 937-945

Chung, Y.I., Kim, J.C., Kim, Y.H., Tae, G., Lee, S.Y., Kim, K. \& Kwon, I.C. (2010). The effect of surface functionalization of PLGA nanoparticles by heparin- or chitosanconjugated Pluronic on tumor targeting. Journal of Controlled Release, Vol. 143, No. 3, pp. 374-382

Danesi, R., Del Bianchi, S., Soldani, P., Campagni, A., La Roccas, R.V., Myers, C.E., Paparelli, A. \& Del Tacca, M. (1993). Suramin inhibits bFGF-induced endothelial cell proliferation and angiogenesis in the chick chorioallantoic membrane. British Journal of Cancer, Vol. 68, No. 5, pp. 932-938

Debergh, I., Van Damme, N., Pattyn, P., Peeters, M. \& Ceelen, W.P. (2010). The lowmolecular-weight heparin, nadroparin, inhibits tumour angiogenesis in a rodent dorsal skinfold chamber model. British Journal of Cancer, Vol. 102, No. 5, pp. 837-843

Depasse, F., González de Suso, M.J., Lagoutte, I., Fontcuberta, J., Borrell, M. \& Samama, M.M. (2003). Comparative study of the pharmacokinetic profiles of two LMWHs-bemiparin (3500 IU, anti-Xa) and tinzaparin (4500 IU, anti-Xa)--administered subcutaneously to healthy male volunteers. Thrombosis Research, Vol. 109, No. 2-3, pp. 109-117

DiGabriele, A.D., Lax, I., Chen, D.I., Svahn, C.M., Jaye, M., Schlessinger, J. \& Hendrickson, W.A. (1998). Structure of a heparin-linked biologically active dimer of fibroblast growth factor. Nature, Vol. 393, No. 6687, pp. 812-817

Dogan, O.T., Polat, Z.A., Karahan, O., Epozturk, K., Altun, A., Akkurt, I. \& Cetin, A. (2011). Antiangiogenic activities of bemiparin sodium, enoxaparin sodium, nadroparin calcium and tinzaparin sodium. Thrombosis Research, Vol. In Press, Corrected Proof, No. pp.

Dredge, K., Hammond, E., Davis, K., Li, C.P., Liu, L., Johnstone, K., Handley, P., Wimmer, N., Gonda, T.J., Gautam, A., Ferro, V. \& Bytheway, I. (2010). The PG500 series: Novel heparan sulfate mimetics as potent angiogenesis and heparanase inhibitors for cancer therapy. Investigational New Drugs, Vol. 28, No. 3, pp. 276-283

Fernández-Tornero, C., Lozano, R.M., Redondo-Horcajo, M., Gómez, A.M., López, J.C., Quesada, E., Uriel, C., Valverdell, S., Cuevas, P., Romero, A. \& Giménez-Gallego, G. (2003). Leads for development of new naphthalenesulfonate derivatives with enhanced antiangiogenic activity. Crystal structure of acidic fibroblast growth factor in complex with 5-amino-2-naphthalenesulfonate. Journal of Biological Chemistry, Vol. 278, No. 24, pp. 21774-21781

Fernández, C., Hattan, C.M. \& Kerns, R.J. (2006). Semi-synthetic heparin derivatives: chemical modifications of heparin beyond chain length, sulfate substitution pattern and N-sulfo/N-acetyl groups. Carbohydrate Research, Vol. 341, No. 10, pp. 1253-1265

Fernández, I.S., Cuevas, P., Angulo, J., López-Navajas, P., Canales-Mayordomo, Á., González-Corrochano, R., Lozano, R.M., Valverde, S., Jiménez-Barbero, J., Romero, 
A. \& Giménez-Gallego, G. (2010). Gentisic acid, a compound associated with plant defense and a metabolite of aspirin, heads a new class of in vivo fibroblast growth factor inhibitors. Journal of Biological Chemistry, Vol. 285, No. 15, pp. 11714-11729

Ferrara, N. (2004). Vascular Endothelial Growth Factor as a Target for Anticancer Therapy. The Oncologist, Vol. 9, No. suppl 1, pp. 2-10

Folkman, J. (1971). Tumor angiogenesis: therapeutic implications. New England Journal of Medicine, Vol. 285, No. 21, pp. 1182-1186

Folkman, J. (1990). What is the evidence that tumors are angiogenesis dependent? Journal of the National Cancer Institute, Vol. 82, No. 1, pp. 4-6

Folkman, J. (1995). Angiogenesis in cancer, vascular, rheumatoid and other disease. Nature Medicine, Vol. 1, No. 1, pp. 27-31

Gagliardi, A., Hadd, H. \& Collins, D.C. (1992). Inhibition of angiogenesis by suramin. Cancer Research, Vol. 52, No. 18, pp. 5073-5075

Gagliardi, A.R.T. \& Collins, D.C. (1994). Inhibition of angiogenesis by aurintricarboxylic acid. Anticancer Research, Vol. 14, No. 2 A, pp. 475-479

Garcia-Fernandez, L., Aguilar, M.R., Fernandez, M.M., Lozano, R.M., Gimenez, G. \& San Roman, J. (2010a). Antimitogenic Polymer Drugs Based on AMPS: Monomer Distribution-Bioactivity Relationship of Water-Soluble Macromolecules. Biomacromolecules, Vol. 11, No. 3, pp. 626-634

Garcia-Fernandez, L., Aguilar, M.R., Fernandez, M.M., Lozano, R.M., Gimenez, G., Valverde, S. \& San Roman J. (2010b). Structure, Morphology, and Bioactivity of Biocompatible Systems Derived from Functionalized Acrylic Polymers Based on 5Amino-2-naphthalene Sulfonic Acid. Biomacromolecules, Vol. 11, No. 7, pp. 17631772

Garcia-Fernandez, L., Halstenberg, S., Unger, R.E., Aguilar, M.R., Kirkpatrick, C.J. \& San Roman, J. (2010c). Anti-angiogenic activity of heparin-like polysulfonated polymeric drugs in 3D human cell culture. Biomaterials, Vol. 31, No. 31, pp. 78637872

Gasowska, K., Naumnik, B., Klejna, K. \& Mysliwiec, M. (2009). The influence of unfractionated and low-molecular weight heparins on the properties of human umbilical vein endothelial cells (HUVEC). Folia Histochemica et Cytobiologica, Vol. 47, No. 1 , pp. $17-23$

Grande, C. \& Caparro, M. (2005). Use of Low-Molecular-Weight Heparins in the Treatment and Secondary Prevention of Cancer-Associated Thrombosis. Seminars in Oncology Nursing, Vol. 21, No. 4, Supplement 1, pp. 41-49

Hassan, H.H.A.M. (2007). Chemistry and biology of heparin mimetics that bind to fibroblast growth factors. Mini-Reviews in Medicinal Chemistry, Vol. 7, No. 12, pp. 1206-1235

Hawkins, M.J. (1995). Clinical trials of antiangiogenic agents. Current Opinion in Oncology, Vol. 7, No. 1, pp. 90-93

Hirsh, J., Warkentin, T.E., Shaughnessy, S.G., Anand, S.S., Halperin, J.L., Raschke, R., Granger, C., Ohman, E.M. \& Dalen, J.E. (2001). Heparin and Low-Molecular-Weight Heparin Mechanisms of Action, Pharmacokinetics, Dosing, Monitoring, Efficacy, and Safety. Chest, Vol. 119, No. 1 suppl, pp. 64S-94S

Jeske, W.P., Hoppensteadt, D., Gray, A., Walenga, J.M., Cunanan, J., Myers, L., Fareed, J., Bayol, A., Rigal, H. \& Viskov, C. (2011). A common standard is inappropriate for 
determining the potency of ultra low molecular weight heparins such as semuloparin and bemiparin. Thrombosis Research, Vol. 128, No. 4, pp. 361-367

Kakkar, A.K. (2004). Low- and ultra-low-molecular-weight heparins. Best Practice and Research: Clinical Haematology, Vol. 17, No. 1, pp. 77-87

Kakkar, A.K., Levine, M.N., Kadziola, Z., Lemoine, N.R., Low, V., Patel, H.K., Rustin, G., Thomas, M., Quigley, M. \& Williamson, R.C.N. (2004). Low molecular weight heparin, therapy with dalteparin, and survival in advanced cancer: The fragmin advanced malignancy outcome study (FAMOUS). Journal of Clinical Oncology, Vol. 22, No. 10, pp. 1944-1948

Khorana, A.A., Sahni, A., Altland, O.D. \& Francis, C.W. (2003). Heparin Inhibition of Endothelial Cell Proliferation and Organization Is Dependent on Molecular Weight. Arteriosclerosis, Thrombosis, and Vascular Biology, Vol. 23, No. 11, pp. 2110-2115

Klerk, C.P.W., Smorenburg, S.M., Otten, H.M., Lensing, A.W.A., Prins, M.H., Piovella, F., Prandoni, P., Bos, M.M.E.M., Richel, D.J., Van Tienhoven, G. \& Büller, H.R. (2005). The effect of low molecular weight heparin on survival in patients with advanced malignancy. Journal of Clinical Oncology, Vol. 23, No. 10, pp. 2130-2135

Kuczka, K., Baum, K., Picard-Willems, B. \& Harder, S. (2009). Long term administration of LMWH - pharmacodynamic parameters under therapeutic or prophylactic regimen of enoxaparin or tinzaparin in neurological rehabilitation patients. Thrombosis Research, Vol. 124, No. 5, pp. 625-630

Kwaan, H.C., Green, D., Pineo, G.F. \& Hull, R.D. (2009) Effects of Anticoagulants on Cancer: Heparins. in Coagulation in Cancer (Rosen, S.T. ed.), Springer US. pp 259-275

Lee, D.Y., Lee, S.W., Kim, S.K., Lee, M., Chang, H.W., Moon, H.T., Byun, Y. \& Kim, S.Y. (2009). Antiangiogenic activity of orally absorbable heparin derivative in different types of cancer cells. Pharmaceutical Research, Vol. 26, No. 12, pp. 2667-2676

Lee, E., Kim, Y.S., Bae, S.M., Kim, S.K., Jin, S., Chung, S.W., Lee, M., Moon, H.T., Jeon, O.C., Park, R.W., Kim, I.S., Byun, Y. \& Kim, S.Y. (2009). Polyproline-type helicalstructured low-molecular weight heparin (LMWH)-taurocholate conjugate as a new angiogenesis inhibitor. International Journal of Cancer, Vol. 124, No. 12, pp. 2755-2765

Liekens, S., Leali, D., Neyts, J., Esnouf, R., Rusnati, M., Dell'era, P., Maudgal, P.C., De Clercq, E. \& Presta, M. (1999). Modulation of fibroblast growth factor-2 receptor binding, signaling, and mitogenic activity by heparin-mimicking polysulfonated compounds. Molecular Pharmacology, Vol. 56, No. 1, pp. 204-213

Liekens, S., Neyts, J., ve, B. \& De Clercq, E. (1997). The sulfonic acid polymers PAMPS [Poly (2-acrylamido-2-methyl-1-propanesuifonie acid)] and related analogues are highly potent inhibitors of angiogenesis. Oncology Research, Vol. 9, No. 4, pp. 173-181

Lindahl, U., Lidholt, K., Spillmann, D. \& Kjellen, L. (1994). More to 'heparin' than anticoagulation. Thrombosis Research, Vol. 75, No. 1, pp. 1-32

Lozano, R.M., Jiménez, M.Á., Santoro, J., Rico, M. \& Giménez-Gallego, G. (1998). Solution structure of acidic fibroblast growth factor bound to 1,3,6-naphthalenetrisulfonate: A minimal model for the anti-tumoral action of suramins and suradistas. Journal of Molecular Biology, Vol. 281, No. 5, pp. 899-915

Lush, R.M., Figg, W.D., Pluda, J.M., Bitton, R., Headlee, D., Kohler, D., Reed, E., Sartor, O. \& Cooper, M.R. (1996). A phase I study of pentosan polysulfate sodium in patients with advanced malignancies. Annals of Oncology, Vol. 7, No. 9, pp. 939-944 
Manetti, F., Cappello, V., Botta, M., Corelli, F., Mongelli, N., Biasoli, G., Borgia, A.L. \& Ciomei, M. (1998). Synthesis and binding mode of heterocyclic analogues of suramin inhibiting the human basic fibroblast growth factor. Bioorganic and Medicinal Chemistry, Vol. 6, No. 7, pp. 947-958

Marchetti, M., Vignoli, A., Russo, L., Balducci, D., Pagnoncelli, M., Barbui, T. \& Falanga, A. (2008). Endothelial capillary tube formation and cell proliferation induced by tumor cells are affected by low molecular weight heparins and unfractionated heparin. Thrombosis Research, Vol. 121, No. 5, pp. 637-645

Miao, H.Q., Ornitz, D.M., Aingorn, E., Ben-Sasson, S.A. \& Vlodavsky, I. (1997). Modulation of fibroblast growth factor-2 receptor binding, dimerization, signaling, and angiogenic activity by a synthetic heparin-mimicking polyanionic compound. Journal of Clinical Investigation, Vol. 99, No. 7, pp. 1565-1575

Middaugh, C.R., Mach, H., Burke, C.J., Volkin, D.B., Dabora, J.M., Tsai, P.K., Bruner, M.W., Ryan, J.A. \& Marfia, K.E. (1992). Nature of the interaction of growth factors with suramin. Biochemistry, Vol. 31, No. 37, pp. 9016-9024

Mousa, S.A. \& Mohamed, S. (2004a). Anti-angiogenic mechanisms and efficacy of the low molecular weight heparin, tinzaparin: anti-cancer efficacy. Oncology reports, Vol. 12, No. 4, pp. 683-688

Mousa, S.A. \& Mohamed, S. (2004b). Inhibition of endothelial cell tube formation by the low molecular weight heparin, tinzaparin, is mediated by tissue factor pathway inhibitor. Thrombosis and Haemostasis, Vol. 92, No. 3, pp. 627-633

Mousa, S.A. \& Petersen, L.J. (2009). Anti-cancer properties of low-molecular-weight heparin: Preclinical evidence. Thrombosis and Haemostasis, Vol. 102, No. 2, pp. 258-267

Naggi, A., Casu, B., Perez, M., Torri, G., Cassinelli, G., Penco, S., Pisano, C., Giannini, G., Ishai-Michaeli, R. \& Vlodavsky, I. (2005). Modulation of the heparanase-inhibiting activity of heparin through selective desulfation, graded $\mathrm{N}$-acetylation, and glycol splitting. Journal of Biological Chemistry, Vol. 280, No. 13, pp. 12103-12113

Nakamura, S., Sakurada, S., Zaki Salahuddin, S., Osada, Y., Tanaka, N.G., Sakamoto, N., Sekiguchi, M. \& Gallo, R.C. (1992). Inhibition of development of Kaposi's sarcomarelated lesions by a bacterial cell wall complex. Science, Vol. 255, No. 5050, pp. 14371440

Nguyen, N.M., Lehr, J.E. \& Pienta, K.J. (1993). Pentosan inhibits angiogenesis in vitro and suppresses prostate tumor growth in vivo. Anticancer Research, Vol. 13, No. 6 A, pp. 2143-2147

Norrby, K. (2000). $2.5 \mathrm{kDa}$ and $5.0 \mathrm{kDa}$ heparin fragments specifically inhibit microvessel sprouting and network formation in VEFG165-mediated mammalian angiogenesis. International Journal of Experimental Pathology, Vol. 81, No. 3, pp. 191-198

Norrby, K. (2006). Low-molecular-weight heparins and angiogenesis. APMIS, Vol. 114, No. 2, pp. $79-102$

Norrby, K. \& Nordenhem, A. (2010). Dalteparin, a low-molecular-weight heparin, promotes angiogenesis mediated by heparin-binding VEGF-A in vivo. APMIS, Vol. 118, No. 12, pp. 949-957

Parish, C.R., Freeman, C., Brown, K.J., Francis, D.J. \& Cowden, W.B. (1999). Identification of sulfated oligosaccharide-based inhibitors of tumor growth and metastasis using novel in vitro assays for angiogenesis and heparanase activity. Cancer Research, Vol. 59, No. 14, pp. 3433-3441 
Park, I.K., Kim, Y.J., Huh, K.M. \& Lee, Y.K. (2010a). Preparation and characterization of heparin-retinoic acid-folic acid conjugates for targeted cancer therapy. Advanced Materials Research, Vol. 93-94, No. pp. 324-327

Park, I.K., Kim, Y.J., Tran, T.H., Huh, K.M. \& Lee, Y.K. (2010b). Water-soluble heparin-PTX conjugates for cancer targeting. Polymer, Vol. 51, No. 15, pp. 3387-3393

Park, J.W., Jeon, O.C., Kim, S.K., Al-Hilal, T.A., Jin, S.J., Moon, H.T., Yang, V.C., Kim, S.Y. \& Byun, Y. (2010). High antiangiogenic and low anticoagulant efficacy of orally active low molecular weight heparin derivatives. Journal of Controlled Release, Vol. 148, No. 3, pp. 317-326

Park, K., Kim, Y.S., Lee, G.Y., Nam, J.O., Lee, S.K., Park, R.W., Kim, S.Y., Kim, I.S. \& Byun, Y. (2007). Antiangiogenic effect of bile acid acylated heparin derivative. Pharmaceutical Research, Vol. 24, No. 1, pp. 176-185

Parmar, N., Berry, L.R., Post, M. \& Chan, A.K.C. (2009). Effect of covalent antithrombinheparin complex on developmental mechanisms in the lung. American Journal of Physiology - Lung Cellular and Molecular Physiology, Vol. 296, No. 3, pp. L394-L403

Perez-Ruiz, A., Montes, R., Carrasco, P. \& Rocha, E. (2002). Effects of a low molecular weight heparin, Bemiparin, and unfractionated heparin on hemostatic properties of endothelium. Clinical and Applied Thrombosis/Hemostasis, Vol. 8, No. 1, pp. 65-71

Pisano, C., Aulicino, C., Vesci, L., Casu, B., Naggi, A., Torri, G., Ribatti, D., Belleri, M., Rusnati, M. \& Presta, M. (2005). Undersulfated, low-molecular-weight glycol-split heparin as an antiangiogenic VEGF antagonist. Glycobiology, Vol. 15, No. 2, pp. 1C$6 \mathrm{C}$

Planès, A. (2003). Review of bemiparin sodium - A new second-generation low molecular weight heparin and its applications in venous thromboembolism. Expert Opinion on Pharmacotherapy, Vol. 4, No. 9, pp. 1551-1561

Presta, M., Oreste, P., Zoppetti, G., Belleri, M., Tanghetti, E., Leali, D., Urbinati, C., Bugatti, A., Ronca, R., Nicoli, S., Moroni, E., Stabile, H., Camozzi, M., Hernandez, G.A., Mitola, S., Dell'Era, P., Rusnati, M. \& Ribatti, D. (2005). Antiangiogenic activity of semisynthetic biotechnological heparins: Low-molecular-weight-sulfated Escherichia coli K5 polysaccharide derivatives as fibroblast growth factor antagonists. Arteriosclerosis, Thrombosis, and Vascular Biology, Vol. 25, No. 1, pp. 7176

Pross, M., Lippert, H., Misselwitz, F., Nestler, G., Krüger, S., Langer, H., Halangk, W. \& Schulz, H.-U. (2003). Low-molecular-weight heparin (reviparin) diminishes tumor cell adhesion and invasion in vitro, and decreases intraperitoneal growth of colonadeno-carcinoma cells in rats after laparoscopy. Thrombosis Research, Vol. 110, No. 4, pp. $215-220$

Rico, S., Antonijoan, R.M., Gich, I., Borrell, M., Fontcuberta, J., Monreal, M., MartinezGonzalez, J. \& Barbanoj, M.J. (2011). Safety Assessment and Pharmacodynamics of a Novel Ultra Low Molecular Weight Heparin (RO-14) in Healthy Volunteers - A First-Time-In-Human Single Ascending Dose Study. Thrombosis Research, Vol. 127, No. 4, pp. 292-298

Ritchie, J.P., Ramani, V.C., Ren, Y., Naggi, A., Torri, G., Casu, B., Penco, S., Pisano, C., Carminati, P., Tortoreto, M., Zunino, F., Vlodavsky, I., Sanderson, R.D. \& Yang, Y. (2011). SST0001, a chemically modified heparin, inhibits myeloma growth and 
angiogenesis via disruption of the heparanase/syndecan-1 axis. Clinical Cancer Research, Vol. 17, No. 6, pp. 1382-1393

Robert, F. (2010). The potential benefits of low-molecular-weight heparins in cancer patients. Journal of Hematology and Oncology, Vol. 3, No. 3, pp. 1-12

Rusnati, M., Oreste, P., Zoppetti, G. \& Presta, M. (2005). Biotechnological engineering of heparin/heparan sulphate: A novel area of multi-target drug discovery. Current Pharmaceutical Design, Vol. 11, No. 19, pp. 2489-2499

Sánchez-Ferrer, C.F. (2010). Bemiparin: Pharmacological profile. Drugs, Vol. 70, No. SUPPL. 2, pp. 19-23

Sideras, K., Schaefer, P.L., Okuno, S.H., Sloan, J.A., Kutteh, L., Fitch, T.R., Dakhil, S.R., Levitt, R., Alberts, S.R., Morton, R.F., Rowland, K.M., Novotny, P.J. \& Loprinzi, C.L. (2006). Low-molecular-weight heparin in patients with advanced cancer: A phase 3 clinical trial. Mayo Clinic Proceedings, Vol. 81, No. 6, pp. 758-767

Takahashi, H., Ebihara, S., Okazaki, T., Asada, M., Sasaki, H. \& Yamaya, M. (2005). A comparison of the effects of unfractionated heparin, dalteparin and danaparoid on vascular endothelial growth factor-induced tumour angiogenesis and heparanase activity. British Journal of Pharmacology, Vol. 146, No. 3, pp. 333-343

Tan, H., Mu, G., Zhu, W., Liu, J. \& Wang, F. (2011). Down-regulation of vascular endothelial growth factor and up-regulation of pigment epithelium derived factor make low molecular weight heparin-endostatin and polyethylene glycol-endostatin potential candidates for anti-angiogenesis drug. Biological and Pharmaceutical Bulletin, Vol. 34, No. 4, pp. 545-550

Tan, H., Yang, S., Feng, Y., Liu, C., Cao, J., Mu, G. \& Wang, F. (2008). Characterization and secondary structure analysis of endostatin covalently modified by polyethylene glycol and low molecular weight heparin. Journal of Biochemistry, Vol. 144, No. 2, pp. 207-213

Thodiyil, P. \& Kakkar, A.K. (2002). Can low-molecular-weight heparins improve outcome in patients with cancer? Cancer Treatment Reviews, Vol. 28, No. 3, pp. 151-155

Tian, J.L., Zhao, Y.Z., Jin, Z., Lu, C.T., Tang, Q.Q., Xiang, Q., Sun, C.Z., Zhang, L., Xu, Y.Y., Gao, H.S., Zhou, Z.C., Li, X.K. \& Zhang, Y. (2010). Synthesis and characterization of Poloxamer 188-grafted heparin copolymer. Drug Development and Industrial Pharmacy, Vol. 36, No. 7, pp. 832-838

Vignoli, A., Marchetti, M., Balducci, D., Barbui, T. \& Falanga, A. (2006). Differential effect of the low-molecular-weight heparin, dalteparin, and unfractionated heparin on microvascular endothelial cell hemostatic properties. Haematologica, Vol. 91, No. 2, pp. 207-214

Vignoli, A., Marchetti, M., Cantalino, E., Diani, E., Bonacina, G. \& Falanga, A. (2010). Very low molecular weight heparins (LMWH) retain the capacity to inhibit endothelial cell migration and capillary-like tube formation induced by tumor cells. Thrombosis Research, Vol. 125, No. Supplement 2, pp. S191-S191

Vignoli, A., Marchetti, M., Cantalino, E., Russo, L., Balducci, D. \& Falanga, A. (2007). Lowmolecular weight heparin (LMWH) bemiparin and ultra-low-MWH RO-14 inhibit lung, breast and leukemia cancer cell-induced endothelial angiogenesis. Thrombosis Research, Vol. 120, No. Supplement 2, pp. S149-S149

Vignoli, A., Marchetti, M., Russo, L., Cantalino, E., Diani, E., Bonacina, G. \& Falanga, A. (2011). LMWH bemiparin and ULMWH RO-14 reduce the endothelial angiogenic 
features elicited by leukemia, lung cancer, or breast cancer cells. Cancer Investigation, Vol. 29, No. 2, pp. 153-161

Von Tempelhoff, G., Harenberg, J. \& Niemann, F. (2000). Effect of low molecular weight heparin (certoparin) versus unfractionated heparin on cancer survival following breast and pelvic cancer surgery: a prospective randomized double-blind trial. International Journal of Oncology, Vol. 16, No. 4, pp. 815-824

Wahl, O., Oswald, M., Tretzel, L., Herres, E., Arend, J. \& Efferth, T. (2011). Inhibition of tumor angiogenesis by antibodies, synthetic small molecules and natural products. Current Medicinal Chemistry, Vol. 18, No. 21, pp. 3136-3155

Wang, X., Li, J., Wang, Y., Cho, K.J., Kim, G., Gjyrezi, A., Koenig, L., Giannakakou, P., Shin, H.J.C., Tighiouart, M., Nie, S., Chen, Z. \& Shin, D.M. (2009). HFT-T, a targeting nanoparticle, enhances specific delivery of paclitaxel to folate receptor-positive tumors. ACS Nano, Vol. 3, No. 10, pp. 3165-3174

Wang, Y., Xiang, J. \& Yao, K. (2010). Target-specific cellular uptake of taxol-loaded heparinPEG-folate nanoparticles. Biomacromolecules, Vol. 11, No. 12, pp. 3531-3538

Wang, Y., Xin, D., Liu, K. \& Xiang, J. (2009a). Heparin-Paclitaxel conjugates using mixed anhydride as intermediate: Synthesis, influence of polymer structure on drug release, anticoagulant activity and in vitro efficiency. Pharmaceutical Research, Vol. 26, No. 4, pp. 785-793

Wang, Y., Xin, D., Liu, K., Zhu, M. \& Xiang, J. (2009b). Heparin-paclitaxel conjugates as drug delivery system: Synthesis, self-assembly property, drug release, and antitumor activity. Bioconjugate Chemistry, Vol. 20, No. 12, pp. 2214-2221

Westmuckett, A.D., Kakkar, V.V., Hamuro, T., Lupu, F. \& Lupu, C. (2001). Bemiparin and fluid flow modulate the expression, activity and release of tissue factor pathway inhibitor in human endothelial cells in vitro. Thrombosis and Haemostasis, Vol. 86, No. 6, pp. 1547-1554

Williamson, J. (1957). Suramin complexes. I. Prophylactic activity against Trypanosoma congolense in small animals. Annals of tropical medicine and parasitology, Vol. 51, No. 4, pp. $440-456$

Williamson, J. \& Desowitz, R.S. (1956). Prophylactic activity of suramin complexes in animal trypanosomiasis. Nature, Vol. 177, No. 4519, pp. 1074-1075

Zamai, M., Caiolfa, V.R., Pines, D., Pines, E. \& Parola, A.H. (1998). Nature of interaction between basic fibroblast growth factor and the antiangiogenic drug 7,7- (carbonylbis[imino-N-methyl-4,2- pyrrolecarbonylimino[N-methyl-4,2-pyrrole]carbonylimino])bis- (1,3- naphthalene disulfonate). Biophysical Journal, Vol. 75, No. 2, pp. 672-682

Zugmaier, G., Lippman, M.E. \& Wellstein, A. (1992). Inhibition by pentosan polysulfate (PPS) of heparin-binding growth factors released from tumor cells and blockage by PPS of tumor growth in animals. Journal of the National Cancer Institute, Vol. 84, No. 22, pp. 1716-1724 


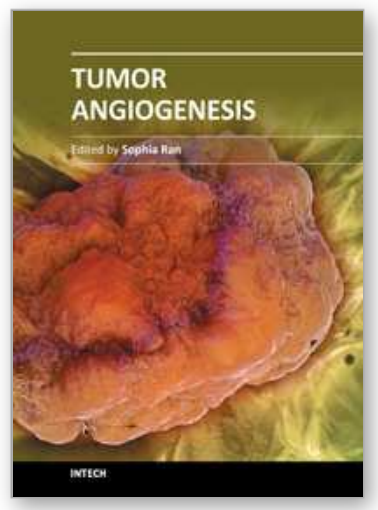

\author{
Tumor Angiogenesis \\ Edited by Dr. Sophia Ran
}

ISBN 978-953-51-0009-6

Hard cover, 296 pages

Publisher InTech

Published online 17, February, 2012

Published in print edition February, 2012

Tumor angiogenesis is the main process responsible for the formation of new blood vessels that promote tumor growth and metastasis. This process is driven by potent pro-angiogenic factors that are predominant in the tumor environment and are produced by both malignant cells and the host cells recruited to the tumor site. Tumor environment is characterized by the imbalance between pro-angiogenic and anti-angiogenic factors, which drives the construction of numerous but structurally defective vessels. These poorly perfused and abnormal vessels significantly contribute to the tumor pathology not only by supporting the expansion of the tumor mass but also by promoting chronic inflammation, enhancing thrombosis, impeding drug delivery, and disseminating tumor cells. These problems associated with tumor vasculature continue to attract great attention of scientists and clinicians interested in advancing the understanding of tumor biology and development of new drugs. This book complies a series of reviews that cover a broad spectrum of current topics related to the pathology of tumor blood vessels including mechanisms inducing new vessels, identification of new targets for inhibition of tumor angiogenesis, and potential clinical use of known and novel anti-angiogenic therapies. The book provides an update on tumor angiogenesis that could be useful for oncologists, cancer researchers and biologists with interests in vascular and endothelial cell behavior in the context of cancer.

\title{
How to reference
}

In order to correctly reference this scholarly work, feel free to copy and paste the following:

María Rosa Aguilar, Luis García-Fernández, Raquel Palao-Suay and Julio San Román (2012). Heparin-Like Drugs with Antiangiogenic Activity, Tumor Angiogenesis, Dr. Sophia Ran (Ed.), ISBN: 978-953-51-0009-6, InTech, Available from: http://www.intechopen.com/books/tumor-angiogenesis/heparin-like-compounds-withantiangiogenic-activity

\section{INTECH}

open science | open minds

\section{InTech Europe}

University Campus STeP Ri

Slavka Krautzeka 83/A

51000 Rijeka, Croatia

Phone: +385 (51) 770447

Fax: +385 (51) 686166

\section{InTech China}

Unit 405, Office Block, Hotel Equatorial Shanghai

No.65, Yan An Road (West), Shanghai, 200040, China 中国上海市延安西路65号上海国际贵都大饭店办公楼 405 单元

Phone: +86-21-62489820

Fax: +86-21-62489821 
www.intechopen.com 
(C) 2012 The Author(s). Licensee IntechOpen. This is an open access article distributed under the terms of the Creative Commons Attribution 3.0 License, which permits unrestricted use, distribution, and reproduction in any medium, provided the original work is properly cited. 